\title{
IN FLUEN CE OF PROPYLENE UN ITS STEREOREGULARITY IN MODIFIED ETHYLENE-PROPYLENE-DIENE ELASTOMERS ON THE OZONE RESISTANCE OF COVULCANIZATES WITH ACRYLONITRILE-BUTADIENE RUBBERS
}

\author{
Nadezhda Livanova ${ }^{1, *}$, Anatoliy Popov ${ }^{1,2}$, \\ Vladimir Shershnev ${ }^{3}$, Gennady Zaikov ${ }^{1}$
}

DOI: dx.doi.org/10.23939/chcht11.01.035

\begin{abstract}
The modification of ethylene-propylene-diene elastomers via the addition of fragments of an accelerating agent to improve their compatibility with acrylonitrilebutadiene rubbers and to reduce the rate of ozone degradation of the polydiene matrix is efficient only in the case of low stereoregularity of propylene units in the ethylene-propylene-diene copolymers when the crosslinking system is added to acrylonitrile-butadiene rubber. When the isotacticity of propylene fragments in the chains of ethylene-propylene-diene elastomers is high, their modification leads to a reduction in the ozone resistance of the crosslinked blend independently of the mode of introduction of the crosslinking system.
\end{abstract}

Keywords: acrylonitrile-butadiene rubber, ethylenepropylene-diene elastomer, ozone-induced degradation, compatibility, interphase layers structure, propylene units, stereoregularity.

\section{Introduction}

In [1-4] the relation of ozone resistance to the volume and structure of the interphase layer and the amounts of crosslinks in the interlayer for covulcanizates of acrylonitrile-butadiene rubbers (NBRs) of various polarities with ethylene-propylene-diene (EPDM) elastomers that differed in the comonomer composition and stereoregularity of propylene units was studied. It was

\footnotetext{
${ }^{1}$ Emanuel Institute of Biochemical Physics, Russian Academy of Sciences, 4, Kosygina St., 119334 Moscow, Russia

${ }^{2}$ Plekhanov Russian University of Economics,

36, Stremyanny Ln., 117997 Moscow, Russia

${ }^{3}$ Lomonosov State Academy of Fine Chemical Technology,

86, Vernadskogo Ave., 11957 Moscow, Russia

*livanova@sky.chph.ras.ru

() Livanova N., Popov A., Shershnev V., Zaikov G., 2017
}

shown that the rate of ozone-induced degradation of the diene matrix is determined by the compatibility of the components, phase structure, the interlayer volume and density, the amount of crosslinks in the interlayer, and the strength of the EPDM network.

It was found in [1-4] that the density of the interfacial layer and the number of interfacial crosslinks depend on the relative amounts of ethylene and propylene units and diene groups, the degree of isotacticity of the propylene chain segments in EPDM, and the isomer composition of the butadiene units in NBR that primarily exist in the trans-1,4-configuration. The most dense and voluminous interlayer with the largest amount of crosslinks provides the most effective protection against ozone degradation to the diene matrix.

The ozone resistance, surface layer structure, and composition of covulcanizates of acrylonitrile-butadiene rubbers containing different amounts of acrylonitrile units with ethylene-propylene terpolymers were studied using the stress relaxation and ESR and FMIR IR spectroscopy techniques. Ethylene-propylene-diene elastomers manufactured by Uniroyal, DSM and domestic EPDM, which differ in the comonomer ratio and in the stereoregularity of propylene sequences, were used [1-4].

In the case of peroxide crosslinking of EPDM, it is possible to estimate the density of the interfacial layer and the number of crosslinks in this layer from deviation of the equilibrium degree of swelling of covulcanizates from additive values in a nonpolar selective solvent, $n$-heptane (the Zappa method) [5, 6]. The deviation toward an increase is provided by a weak interfacial interaction between thermodynamically incompatible polymers, one of which contains polar units. These systems show only local mutual solubility of the segments of nonpolar chain 
fragments with a lower degree of crosslinking of the components than that in the phases [7-10].

The most effective ozone-protection is provided by the compatibility of NBR with EPDM having a large proportion of ethylene units at a high isotacticity of propylene sequences and a moderate amount of diene groups.

In the case of the sulfur vulcanization of EPDM, the above tendencies are preserved.

In [11] the specific features of the structure of the interphase interaction region and its volume are related to the efficiency of inhibition of ozone degradation of the diene elastomer in cured heterophasic blends of BNKS-28 and domestic EPDMs with different compositions and stereoregularities of propylene sequences, and the effect of their modification by means of heating with an accelerating agent and sulfur on the characteristics of covulcanizates.

It was shown that the structural characteristics of EPDM control the efficacy of modification during the addition of NBRs for improvement of such characteristics of the crosslinked blends as ozone resistance and physicomechanical parameters.

In this study, the characteristics of NBR covulcanizates with different contents of polar acrylonitrile units (AN units) and EPDM whose macromolecules contain attached fragments of the accelerating agent have been investigated. It is of interest to estimate the effect of modification on the compatibility of polar copolymers with nonpolar elastomers and the influence of not only the comonomer ratio but also the stereoregularity of propylene sequences. The relationship between the characteristics of the blends and the mode of introducing the crosslinking system into NBR or a mixture of elastomers has been studied.

\section{Experimental}

A heterophase crosslinked blend of NBR and EPDM with the ratio of 70:30 (w/w), which represented a system of interpenetrating crosslinked networks, was studied. Commercial nitrile-butadiene rubbers (trademarks BNKS-18, BNKS-28, and BNKS-40) were used. The AN-unit contents were 18, 28, and $40 \mathrm{wt} \%$, respectively, and the values of the Mooney viscosity (at $373 \mathrm{~K}$ ) were 40-50, 45-65, and 45-70 rel. units, respectively, according to Russia technical specifications. They contained no more than $5 \mathrm{wt} \%$ calcium stearate and $0.35 \mathrm{wt} \%$ ionol. The weight loss during drying did not exceed $0.8 \%$.

The changes in the weight of the vulcanizate in an isooctane-toluene mixture were below 65,34 , and $25 \%$ for BNKS-18, BNKS-28, and BNKS-40, respectively. For all the NBRs, the solubility in methyl ethyl ketone was no less than $95 \%$. The content of trans-1,4-, 1,2-, and cis-1,4-units of butadiene was estimated via IR spectroscopy (bands at 967,911 , and $730 \mathrm{~cm}^{-1}$ ) [12] with the use of extinction coefficients from [13] (Table 1).

The domestic EPDMs had different compositions and stereoregularities of propylene units. The weight losses during drying were below $0.5 \%$. The weight fractions of ash, vanadium, alcohol-toluene extract, and antioxidants Naphthame-2 or Agidol-2 were $<0.2 \%$, $<0.008 \%$, $<4 \%$, and within $0.15-0.30 \%$, respectively. Elastokam 7505 contained no more than $0.1 \mathrm{wt} \%$ ash and $0.15 \%$ of the stabilizing agent, Agidol-2; the weight loss during drying was below $0.1 \%$.

Table 1

Isomeric composition of butadiene units in different $\mathrm{AN}$-butadiene copolymers

\begin{tabular}{|c|c|c|c|}
\hline \multirow{2}{*}{ Copolymer } & \multicolumn{2}{|c|}{ Content of units, \% } \\
\cline { 2 - 4 } & trans-1,4- & $1,2-$ & 9.8 \\
\hline BNKS-18 & 82.0 & 8.2 & 9.2 \\
\hline BNKS-28 & 76.4 & 14.4 & 2.6 \\
\hline BNKS-40 & 93.0 & 4.4 & \\
\hline
\end{tabular}

Table 2

Characteristics of domestic EPDM

\begin{tabular}{|c|c|c|c|c|}
\hline EPDM trademark & $\begin{array}{c}\text { Mooney viscosity } \\
\eta, \text { rel. units }\end{array}$ & $\begin{array}{c}\text { Ethylene: propylene, } \\
\text { wt \% }\end{array}$ & $\alpha, \%$ & $\begin{array}{c}\text { Content of ethylydene- } \\
\text { norbornene, wt } \%\end{array}$ \\
\hline EPDM-40 & $36-45$ & $70 / 30$ & 29.0 & 4.0 \\
\hline Elastokam 6305 & 67 & $74 / 26$ & 9.5 & 5.4 \\
\hline EPDM-60(I) & 60 & $60 / 40$ & 13.0 & 4.0 \\
\hline EPDM-60(II) & 62 & $60 / 40$ & 13.0 & 6.7 \\
\hline Elastokam 7505 & 83 & $60 / 40$ & 9.5 & 5.1 \\
\hline
\end{tabular}


Table 2 shows the data on the Mooney viscosity; the content of ethylene, propylene, and ethylidenenorbornene units (according to the manufacturer's data); and the degree of isotacticity of propylene sequences of EPDM chains, $\alpha$, estimated via IR spectroscopy $[14,15]$.

The composition of sulfur-containing crosslinking systems for NBR and EPDM includes stearic acid, zinc oxide, mercaptobenzothiazole, tetramethylthiuram disulfide, and sulfur [11]. Each of the rubbers was mixed with its crosslinking system on rolls at $313-333 \mathrm{~K}$ for $15 \mathrm{~min}$. Then, the blends of the rubbers were prepared under the same conditions. Vulcanization was performed at $428 \mathrm{~K}$ for $20 \mathrm{~min}$ at the pressure of 19.6 MPa. During rubber blending and vulcanization, the redistribution of vulcanizing agents took place [16]. For the peroxide vulcanization of EPDM, Peroximon F-40 on a carrier was used; its content was 5.5 weight parts [3, 4].

To improve the compatibility and crosslinking of the components, domestic EPDM was modified by heating with the accelerating agent and sulfur for $30 \mathrm{~min}$ at $433 \mathrm{~K}$ (in the absence of crosslinking of EPDM).

The crosslinking system was introduced via mixing with EPDM modified by the sulfur-containing accelerating agent via two routes: (i) mixing with NBR with the same composition of the vulcanizing group as that in the case of the unmodified EPDM and (ii) introduction into the mixture of elastomers (the common vulcanizing group).

In the case of peroxide crosslinking of EPDM [1-4] the deviation of $Q_{e q}$ from additive values $-\alpha$ was calculated by the formula [6]:

$$
-\alpha=\frac{Q_{a d}-Q_{e q}}{Q_{a d}-Q_{2}} \cdot 100 \%
$$

where $Q_{e q}$ is the equilibrium degree of swelling of a covulcanizate; $Q_{a d}$ is the additive value of swelling in a given solvent, as calculated from the equilibrium degree of swelling of vulcanizates for each rubber; and $Q_{2}$ is the share of swelling of the second elastomer (BNR).

The ozone resistance of the blends was studied via the method of stress relaxation at ozone concentration of $8.5 \cdot 10^{-5} \mathrm{~mol} / \mathrm{l}, 303 \mathrm{~K}$ and at the tensile strain of $30-150 \%$ on an IKhF-2 relaxometer [3, 4]. Relaxation rate, $v_{r}$, in the ozone-containing medium in the steady-state region next to the region of the fast physical relaxation reflects the kinetics of accumulation of chain ruptures in the diene matrix (Fig. 1). The efficacy of retardation of degradation during the introduction of EPDM, $v_{r}^{\text {rel }}$, corresponds to the intensity of the decrease in the rate in the presence of the ozone-resistant component relative to that in the presence of the NBR vulcanizate.

The region of a low relaxation rate with quasiequilibrium stress $\sigma^{*}$ reflects the strength of the EPDM network because it represents the superposition of stresses in the network and in the matrix connected through interfacial layers [3, 4]. The absence of the continuous structure of EPDM or its breakdown during tensile drawing is accompanied by a stress drop to zero due to propagation and merging of ozone microcracks.

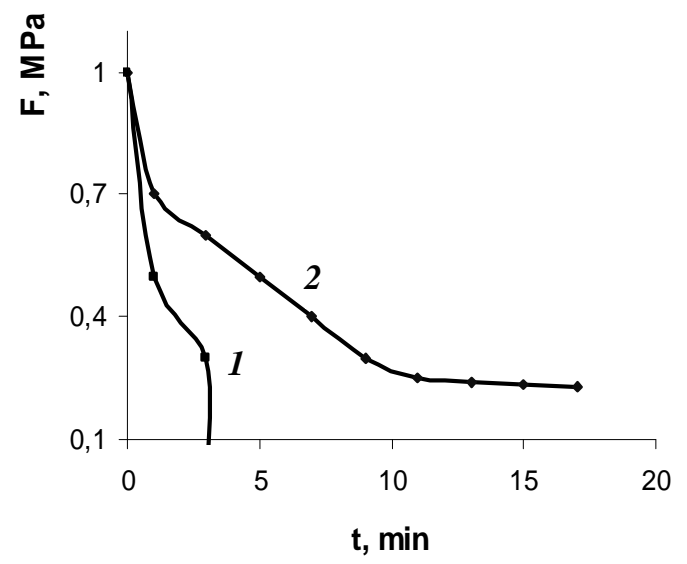

Fig. 1. Decay curves of force $F$ in drawn specimens of NBR covulcanizates containing 15 (1) and 30 (2) phr EPDM. See the text for details

The physicomechanical tests of the covulcanizates were performed according to the standards on an Instron universal tensile machine at a strain rate of $500 \mathrm{~mm} / \mathrm{min}$. The error of breaking-strength measurements was $\pm 10 \%$.

\section{Results and Discussion}

It was shown in [1-4] that the most developed interfacial layer is formed in the blend of NBR and EPDM with a high content of ethylene units neighboring stereoregular propylene chains that are integrated with individual AN units. The above EPDMs show the maximum efficacy in retardation of the ozone degradation of polydiene $[3,4]$.

In the case of low degree of isotacticity of propylene units, $\alpha$, compatibilization is possible only with butadiene units of NBR. In this case, the density of the interfacial layer and the number of interfacial crosslinks depend on the ratio between the isomers of the butadiene units that primarily exist in the trans-1,4configuration (Table 1). The higher the overall content of cis-1,4- and 1,2-isomers, the higher the volume of the interfacial layer and the higher the degree of crosslinking of the phases [14]. It was found in [17] that the isomers of butadiene units that exist in low concentrations and disturb the geometric similarity of chains reduce the dimensions of the ordered structures preventing interfacial interaction. With an increase in the content of polar AN units in NBR and a decrease in the volume of the interfacial layer, the protective effect of the saturated component decreases. 
Ethylene units are compatible with all butadiene isomers. The efficacy of retardation of degradation is minimum for the butadiene-nitrile EPDM rubber with a high content of propylene units and a low degree of isotacticity.

The chemical mechanism of the effect on the stereoregularity of the propylene units and cross-linking of the copolymer in improving resistance to ozone, is presumably as follows. In [18-20] by IR and EPR spectroscopy and TMA investigated the molecular and supramolecular structure of EPDM elastomers. It was shown that in copolymers with high degree of isotactic propylene sequences not only ethylene but also propylene supramolecular structures are formed. Ordered structures are unapproachable to low molecular weight compounds. Sorption latest happening in the defective regions formed violations stereoregularity of the comonomer units. Thus, the formation of supramolecular structures in large quantities leads to the concentration of low molecular weight compounds in the defective areas, including double bonds which crosslink the copolymers. As a result, the number of cross-links in EPDM may increase, contributing to the strength of the EPDM network and, as a consequence, increasing the ozone resistance of elastomers blends.

In the case of the sulfur vulcanization of EPDM, the degree of crosslinking of the phases in the interfacial layer cannot be estimated from the deviation of equilibrium degree of swelling $Q_{r}$ in $n$-heptane from the additive value, because of the high content of the extracted species in the crosslinked mixture $[5,6]$. Therefore, in this study, the structure of the crosslinked blends, the intensity of interfacial interaction, and the degree of crosslinking of the phases for unmodified and modified EPDMs were estimated from the equilibrium swelling in $n$-heptane and toluene. The ratio between the number of crosslinks and physical junctions was calculated from the data on swelling in the above solvents: $1 / Q_{h}: 1 / Q_{t}=Q_{t} / Q_{h}$. In this case, the following speculations are taken into account.

The equilibrium swelling of NBR in both solvents decreases in almost direct proportion to an increase in the content of acrylonitrile units (Fig. 2). The mixtures are crosslinked by the same curing system. The equilibrium degree of swelling decreases not only because of the increase in the number of crosslinks in NBR due to an increase in the concentration of the crosslinking agents in the butadiene part of copolymer but also because of changes in the affinity of a solvent for a polymer [21].

Similar dependences for the covulcanizates are nonlinear, and the degree of swelling is higher. These results are explained by the low compatibility of the components, loosening of the phases, and formation of a transition layer with a density lower than that in the phases and a lower degree of crosslinking of the components. The equilibrium swelling of BNR in $n$-heptane is low in comparison to that in toluene (Figs. $2 \mathrm{a}, 2 \mathrm{~b}$, curves 7) and lower than $Q_{r}$ of the EPDM vulcanizates in $n$-heptane. Hence, the degree of swelling of the covulcanizates in $n$-heptane primarily reflects the degree of crosslinking of the EPDM phase and the interfacial layer. At the same time, swelling of elastomers in toluene corresponds to the overall degree of crosslinking. Hence, ratio $Q_{t} / Q_{h}$ characterizes the fraction of crosslinks in the EPDM phase and between the phases with respect to the overall number of crosslinks.

In the case of peroxide crosslinking of domestic EPDMs [1, 3, 4], there is a linear dependence of this ratio with an increase in the content of AN in NBR (Fig. 3). The slopes of the curves depend on the difference in the intensity of decay in the affinity of these solvents for NBR; hence, this value is not considered. Thus, in the case of the peroxide crosslinking of EPDM (Fig. 3), the fraction of interfacial crosslinking in the overall number of crosslinks slightly decreases with a decrease in the volume of the regions of segmental solubility when the content of the polar units in NBR is increased. When Peroximon F-40 on a carrier, which is incapable of diffusion displacements, is used $[1,3,4]$, the degree of crosslinking of the EPDM phase is likely controlled by its concentration.

A similar dependence is observed for DSM 712 [3] that contains $48 \mathrm{wt} \%$ propylene units and has a degree of isotacticity of $11 \%$. For EPDM R 512 that contains $32 \mathrm{wt} \%$ propylene units and has $\alpha=20 \%$ after peroxide vulcanization, ratio $Q_{l} / Q_{h}$ is higher than that for EPDM with a low stereoregularity of the propylene units (Fig. 2). Therefore, for EPDM with a high content of ethylene units and a large value of $\alpha$, the volume of the interfacial layer in the blends with all NBRs is higher $[4,5]$.

During the sulfur vulcanization of unmodified EPDM-60(I) and EPDM-40, the number of crosslinks in the interfacial layer with respect to the overall number of crosslinks $\left(Q_{t} / Q_{h}\right)$ decreases with an increase in the content of the polar units in NBR (Fig. 4a). For EPDM-40 with a high degree of isotacticity of propylene microblocks (integration with individual AN units is possible [1, 2, 4]), this dependence is almost linear. For EPDM-60(I) with a low degree of isotacticity, whose segments are compatible only with the butadiene units of NBR, this dependence is nonlinear. In the blends with BNKS-18 and BNKS-40, the fraction of crosslinks in the interfacial layers is lower than that in EPDM-40. For BNKS-28 with the maximum content of cis-1,4- and 1,2-units assisting compatibilization $[1,2,4,17]$, the volume of regions of segmental solubility for EPDM-60 (I) is increased.

For Elastokam 6305 with a high content of diene, which is compatible only with the fragments of chains containing cis-1,4- and 1,2-units of butadiene [4, 11], there is an increase in the fraction of the crosslinks in the interfacial layer with an increase in the content of the above elastomers (Fig. 4b). 

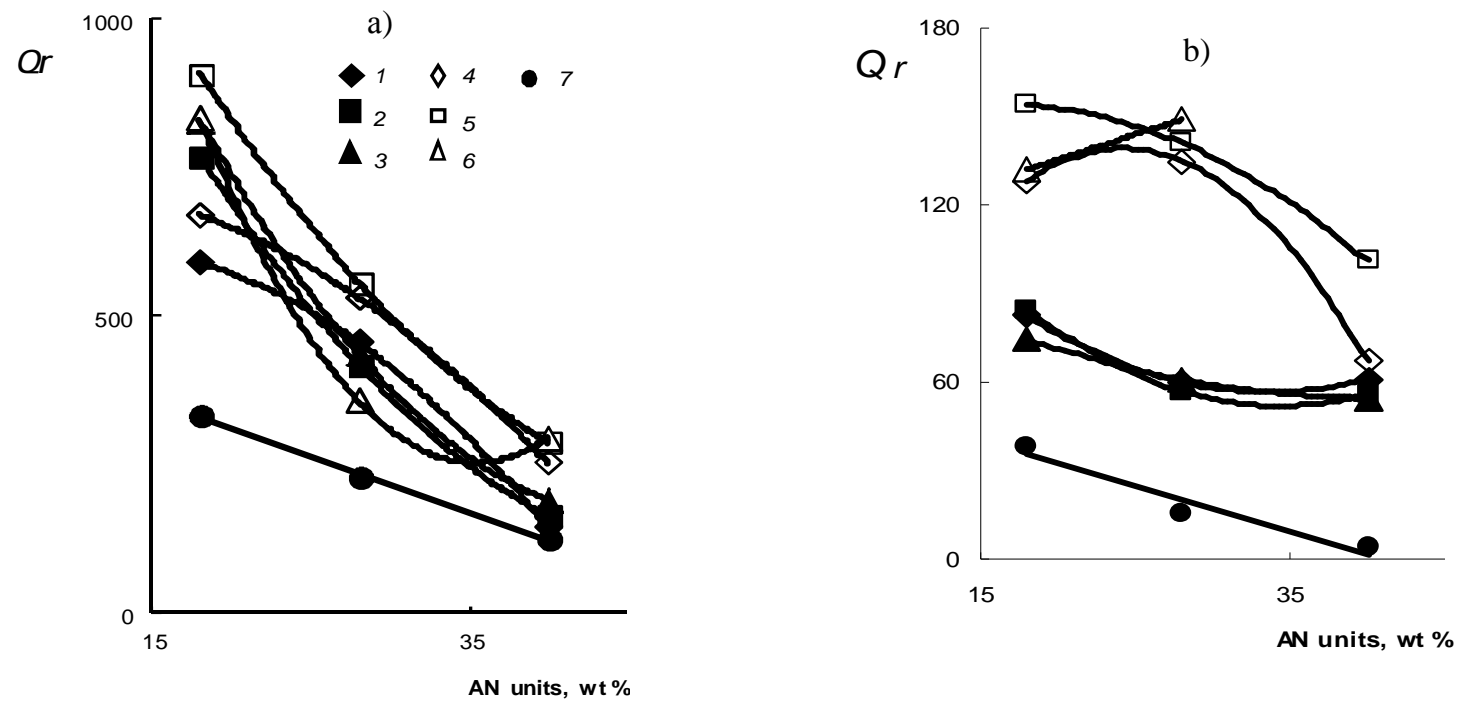

Fig 2. Equilibrium swelling in toluene (a) and $n$-heptane (b) for the NBR covulcanizates

with Elastokam $6305(1,4)$; EPDM-60(I) $(2,5)$ and EPDM-40 $(3,6)$ plotted against the content of AN-units:

unmodified samples (1-3), samples modified by sulfur the containing accelerating agent (4-6) and NBR vulcanizates (7)

Fig. 3. $Q_{t} / Q_{h}$ plotted against the content of AN-units in BNR for covulcanizates of NBR with domestic EPDM and EPDM 712 (DSM) (1) and R 512 (2) after peroxide crosslinking

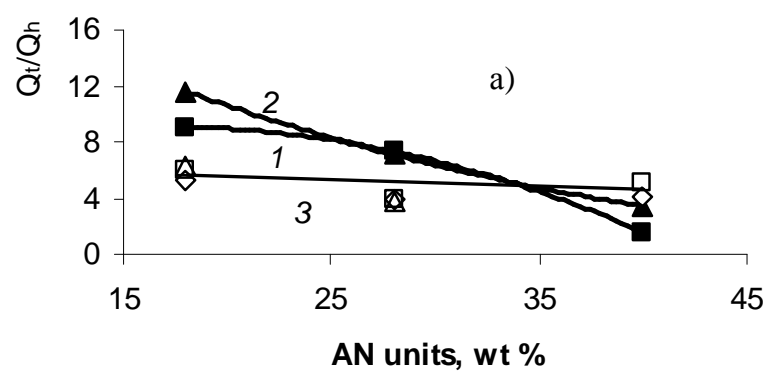

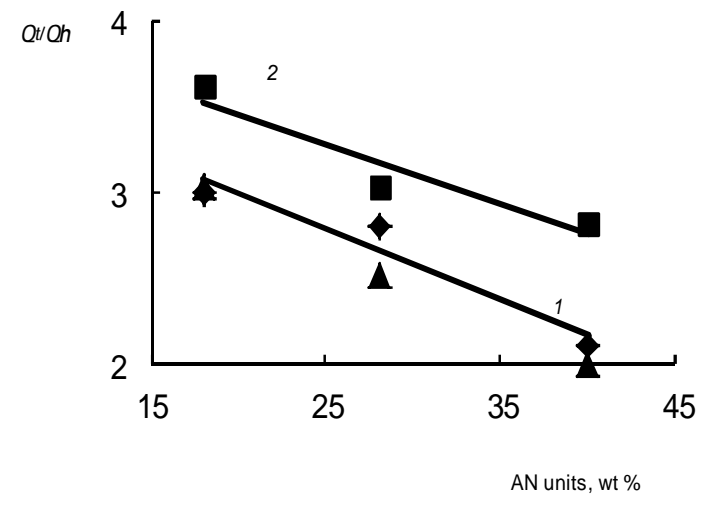

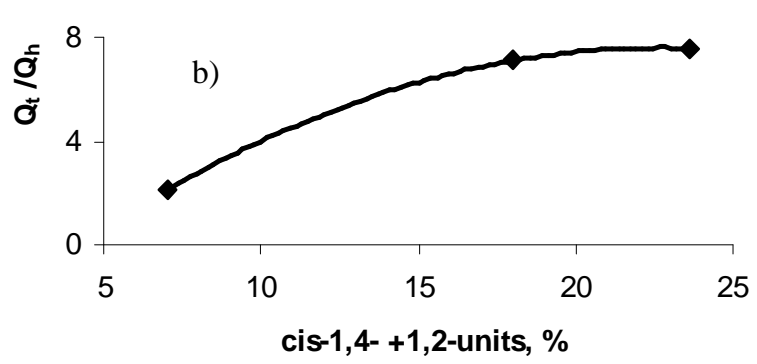

Fig. 4. $Q_{t} / Q_{h}$ plotted against the AN units content (a) for NBR covulcanizates with unmodified EPDM-60(I) (1); unmodified EPDM-40 (2), and EPDM modified by the accelerating agent (3); $Q_{t} / Q_{h}$ plotted against the content of cis-1,4- and 1,2-units (b) for NBR covulcanizates with unmodified Elastokam 6305

Table 3 presents data on the efficacy of protecting NBR from the action of ozone with the use of various EPDMs: the intensity of ozone degradation rate $v_{r}^{r e l}$ and the strength of the EPDM network, $\sigma^{*}$. In addition, this table shows content $m$ of the sol fraction in $n$-heptane for peroxide crosslinking or toluene for sulfur vulcanization. This table shows data for the blends with EPDM for peroxide and sulfur crosslinking and for modification with the sulfurcontaining accelerating agent during introduction of the crosslinking system into NBR or the mixture of elastomers (the common crosslinking group). 
Note that the ozone-resistant effect of the unmodified EPDM during sulfur crosslinking is higher than that during peroxide crosslinking. This reasoning largely agrees with higher values of $Q_{t} / Q_{h}$ for the above blends (Figs. 3, 4). The only exceptions are EPDM-60(I) with a low content of diene and Elastokam 7505 with a high Mooney viscosity in the blends with BNKS-28 $\left(v_{r}^{\text {rel }}=2.3 ; \sigma^{*}=0\right)$.

The unmodified EPDM-40 with a very high degree of isotacticity of propylene microblocks $(29 \%)$ is the most efficient for retarding the ozone degradation of NBR (Table 3). Chain fragments of such EPDMs [1-4] are compatible not only with butadiene but also with individual polar units of NBR; as a result, the volume of the interfacial layer increases and the density of crosslinks locally decreases [1-4]. Consequently, in the mixture with
BNKS-28 (the maximum volumes of regions of segmental solubility) $[1-4,17]$, network strength $\sigma^{*}$ of EPDM-40, as in other EPDMs, is lower than that in the covulcanizates with NBR but with different contents of AN units.

In contrast to EPDM-40, the copolymers with a low stereoregularity of propylene units (Elastokam 6305 and EPDM-60(I)), which are compatible only with butadiene units, provide less effective protection of the diene elastomer from ozone degradation (Table 3). When the content of diene is high, the protection of BNKS-28 by EPDM-60(II) is better than that of Elastokam 7505 with a lower content of ethylydenenorbornene and a high Mooney viscosity. In the latter case, during peroxide crosslinking, $v_{r}^{r e l}=1.9$ and $\sigma^{*}=0.10$; during sulfur crosslinking, $v_{r}^{r e l}=2.3$ and $\sigma^{*}=0$.

Table 3

Characteristics of EPDM vulcanizates and covulcanizates with NBR

\begin{tabular}{|c|c|c|c|c|c|c|c|c|c|c|}
\hline \multirow{2}{*}{ EPDM } & \multirow{2}{*}{ Mode of crosslinking } & $v_{r}^{r e l}$ & $\sigma^{x}, \mathrm{MPa}$ & $m, \%$ & $v_{r}^{r e l}$ & $\sigma^{x}, \mathrm{MPa}$ & $m, \%$ & $v_{r}^{\text {rel }}$ & $\sigma^{x}, \mathrm{MPa}$ & $m, \%$ \\
\hline & & \multicolumn{3}{|c|}{ BNKS - 28} & \multicolumn{3}{|c|}{ BNKS -18 } & \multicolumn{3}{|c|}{ BNKS - 40} \\
\hline \multicolumn{11}{|c|}{ Butadiene-nitrile rubbers } \\
\hline & & - & 0 & 5.3 & - & 0 & 4.2 & - & 0 & 1.9 \\
\hline \multicolumn{11}{|c|}{ Elastokam 6305} \\
\hline Unmodified & F-40 & 2.2 & 0.11 & 4.1 & 11.6 & 0.34 & - & 2.0 & 0 & 2.3 \\
\hline Unmodified & Sulfur & 4.5 & 0.16 & 21.0 & 20.5 & 0.35 & 22.3 & 2.1 & 0.19 & 18.7 \\
\hline Modified & Sulfur & 11.2 & 0.18 & 4.7 & 18.3 & 0.27 & 3.1 & 1.8 & 0.23 & 11.0 \\
\hline Modified & $\begin{array}{c}\text { Sulfur } \\
\text { (common curing group) }\end{array}$ & 6.9 & 0.20 & 2.1 & - & - & - & 1.1 & 0 & 1.0 \\
\hline \multicolumn{11}{|c|}{ EPDM-60(I) } \\
\hline Unmodified & $\mathrm{F}-40$ & 2.8 & 0.16 & 4.1 & 12.1 & 0.30 & - & 3.2 & 0.08 & 4.1 \\
\hline Unmodified & Sulfur & 3.7 & 0 & 27.0 & 49.1 & 0.28 & 30.9 & 2.0 & 0.15 & 1.0 \\
\hline Modified & Sulfur & 8.5 & 0.15 & 5.0 & 19.6 & 0.24 & 4.1 & 3.0 & 0 & 0 \\
\hline Modified & $\begin{array}{c}\text { Sulfur } \\
\text { (common curing group) }\end{array}$ & 1.9 & 0 & 1.8 & - & - & - & 2.7 & 0 & 3.0 \\
\hline \multicolumn{11}{|c|}{ EPDM-40 } \\
\hline Unmodified & $\mathrm{F}-40$ & 1.8 & 0.10 & 6.9 & 48.0 & 0.27 & - & 2.9 & 0.15 & - \\
\hline Unmodified & Sulfur & 6.4 & 0.16 & 27.0 & 41.6 & 0.31 & 27.7 & 6.2 & 0.36 & 23.0 \\
\hline Modified (at $433 \mathrm{~K}$ ) & Sulfur & 5.7 & 0.13 & 8.2 & 4.5 & 0 & 4.9 & - & - & - \\
\hline Modified (at $443 \mathrm{~K}$ ) & Sulfur & 2.6 & 0 & 1.0 & - & - & - & - & - & - \\
\hline Modified (at $433 \mathrm{~K}$ ) & $\begin{array}{c}\text { Sulfur } \\
\text { (common curing group) }\end{array}$ & 1.8 & 0.07 & 4.3 & - & - & - & - & - & - \\
\hline \multicolumn{11}{|c|}{ EPDM-60(II) } \\
\hline Unmodified & F-40 & 1.8 & 0.13 & 3.9 & - & - & - & - & - & - \\
\hline Unmodified & Sulfur & 5.7 & 0.18 & 26.3 & - & - & - & - & - & - \\
\hline Modified & Sulfur & 4.8 & 0.12 & 3.6 & - & - & - & - & - & - \\
\hline Modified & $\begin{array}{c}\text { Sulfur } \\
\text { (common curing group) }\end{array}$ & 5.1 & 0.18 & 5.8 & - & - & - & - & - & - \\
\hline
\end{tabular}

Table 4

$Q_{t} / Q_{h}$ and content of the sol fraction $m, \%$ in the NBR covulcanizates with the modified EPDM after introduction of the cure system into (numerator) NBR and (denominator) the blend of elastomers

\begin{tabular}{|l|r|c|c|c|}
\hline \multirow{2}{*}{ EPDM } & $Q_{t} / Q_{h}$ & $m, \%$ & $Q_{\downarrow} / Q_{\mathrm{h}}$ & \multicolumn{2}{c|}{ BNKS-40 } \\
\cline { 2 - 5 } & \multicolumn{2}{|c|}{ BNKS-28 } & \multicolumn{2}{c|}{1} \\
\hline Elastokam 6305 & $3.9 / 3.3$ & $4.7 / 2.1$ & $4.1 / 3.8$ & $18.7 / 1.0$ \\
\hline EPDM-60(I) & $3.9 / 3.6$ & $5.0 / 1.8$ & $5.1 / 2.5$ & - \\
\hline EPDM-60(II) & $3.5 / 3.2$ & $3.6 / 5.8$ & - & - \\
\hline EPDM-40 & $3.7 / 3.0$ & $8.2 / 4.3$ & - & - \\
\hline
\end{tabular}


With consideration for the high initial efficacy of EPDM-40, its modification by the sulfur-containing accelerating agent does not lead to improvement in the ozone resistance of the blend. When the heating temperature increases from $433-443 \mathrm{~K}$ for the mixtures of BNKS-28 with the accelerating agent and sulfur, the ozone resistance decreases. In [11], this effect has been explained in terms of EPR spectroscopic data. It was shown that EPDM-40 with a high degree of isotacticity of propylene units contains ordered regions formed by propylene sequences and regions with a mixed composition that contain ethylene and propylene chain fragments. The heat treatment of EPDM-40 during its modification with the dissociation of propylene supramolecular structures (the maximum dissociation temperature is $443 \mathrm{~K}$ [19]) and their formation during cooling leads to the concentration of chemical reagents in relatively small (by volume) disordered regions. As was shown in [11], with an increase in the modification temperature, the molecular dynamics of the EPDM-40 phase in the covulcanizates slows down. This behavior attests the intra phase crosslinking of EPDM, which is confirmed by a marked decrease in the content of the sol fraction in the covulcanizates with an increase in the temperature of heating with the accelerating agent and sulfur (Table 3). As a result, the compatibilization of the components is hindered, and the ozone protective effect of EPDM decreases.

In contrast to the modification of EPDM-40, the modification of Elastokam 6305 and EPDM-60(I) in the mixtures with BNKS-28 with a high content of cis-1,4and 1,2-units by the accelerating agent and sulfur $[4,11]$ leads to an increase in the ozone resistance of the blends with regard to $v_{r}^{\text {rel }}$ and $\sigma^{*}$ (Table 3 ).

In the mixtures with BNKS-18 and BNKS-40 with a higher order of trans-1,4-isomers (with a lower content of cis-1,4- and 1,2- units), their efficacy does not increase, because of reduced compatibilization [17]. In the least compatible crosslinked mixtures with BNKS-40 with the minimum volume of regions of segmental solubility, the modification of Elastokam 6305 provides a moderate effect, while EPDM-60(I) with a low content of diene reduces compatibilization and crosslinking of the phases and $\sigma^{*}$ decreases to zero (a strain of $30 \%$ ).

According to the EPR data, the molecular mobility in the vulcanizates of Elastokam 6305 and its covulcanizates with NBR before and after modification with the sulfur-containing accelerating agent is the same or higher than that in EPDM-40 [11]. The above EPDMs do not contain the ordered structures of the propylene units that break down at high temperatures. A complete dissociation of fluctuation structures formed by ethylene units occurs at $413 \mathrm{~K}$, which is below the vulcanization temperature. The heat treatment of the elastomer ( $433 \mathrm{~K}$ ) does not lead to any deterioration of its compatibilization with NBR.
The modification of EPDM-60(II) with a high content of diene turns out to be inefficient for improvement of the ozone resistance of covulcanizates (Table 3). In addition, the modification of Elastokam 7505 with a high Mooney viscosity does not provide any increase in the ozone resistance of the blend based on BNKS-28 $\left(v_{r}^{r e l}=2.6\right.$ and $\left.\sigma^{*}=0\right)$.

When the modified EPDMs are used, the content of the sol fraction in the covulcanizates markedly decreases owing to an increase in the degree of crosslinking of the EPDM phase.

For EPDMs modified by the sulfur-containing accelerating agent, ratio $Q_{t} / Q_{h}$ is almost the same (Fig. 4a). Differences in the intensity of the interaction of EPDM with the NBR phase of different polarities diminish because they are controlled by the number of the bonded radicals of the accelerating agent. These radicals interact with sulfur with the participation of the vulcanization promoter $\mathrm{ZnO}, \alpha$-methylene groups of the diene unit, and the ternary carbon atoms of the AN unit. As a result, the number of crosslinks along the entire interfacial boundary (not only in the regions of segmental solubility) and the overall number of crosslinks increase. Therefore, ratio $Q_{t} / Q_{h}$ for the blends with the modified EPDMs does not reflect the degree of crosslinking of the components in the interfacial layer.

This evidence shows that, when EPDM is modified with the sulfur-containing accelerating agent, the ozone resistance increases only for the BNKS-28-based covulcanizates using the elastomers with the preferential atactic configuration of propylene units and contents of diene groups of 4 and $5.4 \%$.

Therefore, it may be concluded that a negative effect occurs owing to the introduction of accelerating groups into EPDM with a high degree of isotacticity of propylene units that, as was shown earlier, are initially compatibilized not only with butadiene but also with AN units $[1-4,11]$ and that ensure better protection of the polybutadiene matrix from ozone attack.

The above data were obtained for the introduction of the cure system into NBR. In general, the introduction of the same crosslinking agents into the blend of elastomers containing EPDM modified by the sulfur containing accelerating agent reduces the ozone resistance (Table 3); the exception is EPDM-60(II) in its blend with BNKS-28. In the case of a common curing group, the number of crosslinks in the interfacial layer is lower than that during the introduction of the cure system into NBR. This circumstance affects the ozone resistance of the covulcanizates (Table 4). In this case, the content of the sol fraction decreases owing to the growth of lateral crosslinks in the EPDM phase. When $v_{r}^{r e l}$ the strain is $30 \%$, an increase in these crosslinks should be accompanied by stress redistribution onto the above 
chemical bonds and a decrease in stress on the unsaturated bonds of the butadiene chain units. As a result, stress approaches critical values, at which the rate of degradation of the diene matrix is maximum.

The modification of EPDM critically changes the physico-mechanical characteristics of the covulcanizates. Fig. 5 presents conditional tensile strength $\sigma_{b r}$ for the blends with unmodified EPDM (Fig. 5a) and EPDM modified by the sulfur-containing accelerating agent (Fig. 5b). Fig. 6 presents the relative elongation at break, $\varepsilon_{b r}$, for the same species. For the unmodified EPDMs, $\sigma_{b r}$ slightly increases with an increase in the overall content of cis-1,4- and 1,2-units of butadiene in NBR, and this increase is associated with the structure of the interfacial layer and the increase in its volume, density, and number of crosslinks $[1,2,11]$. This reasoning agrees with the speculations that, in polymer blends, the interfacial layer is the weakest structural element $[7,8]$.

For the modified EPDMs, $\sigma_{r}$ increases with an increase in the content of AN units in NBR. This result validates the conclusion that the degree of crosslinking of the components along interfacial boundary increases during the addition of radicals of the accelerating agent. The maximum increase in the conditional tensile strength is observed after mixing with the modified EPDM with a low degree of isotacticity of propylene units and an increased content of diene (Elastokam 6305).

For the blends with unmodified EPDM, the relative elongation at break is practically independent of the content of AN-units. For EPDM modified by the sulfurcontaining accelerating agent, $\varepsilon_{b r}$ increases with an increase in the content of AN.

Therefore, the effect of the EPDM structure (Table 1) on the features of the development of the interfacial layer in the crosslinked blends with BNR, which are observed during peroxide crosslinking, is preserved in the case of sulfur vulcanization and modification of EPDM. The best results are obtained for the modification of EPDM with a low stereoregularity of propylene units when the cure system is introduced into BNR. In the case of the common curing group, the characteristics become worse. When the degree of isotacticity of the propylene sequences is high (EPDM-40), the content of diene is high (EPDM-60(II)), and the Mooney viscosity is high (Elastokam 7505), the modification of the copolymer does not provide any increase in the ozone resistance. In many cases, modification results in improvement of the rubbery characteristics and causes an increase in the conditional tensile strength.
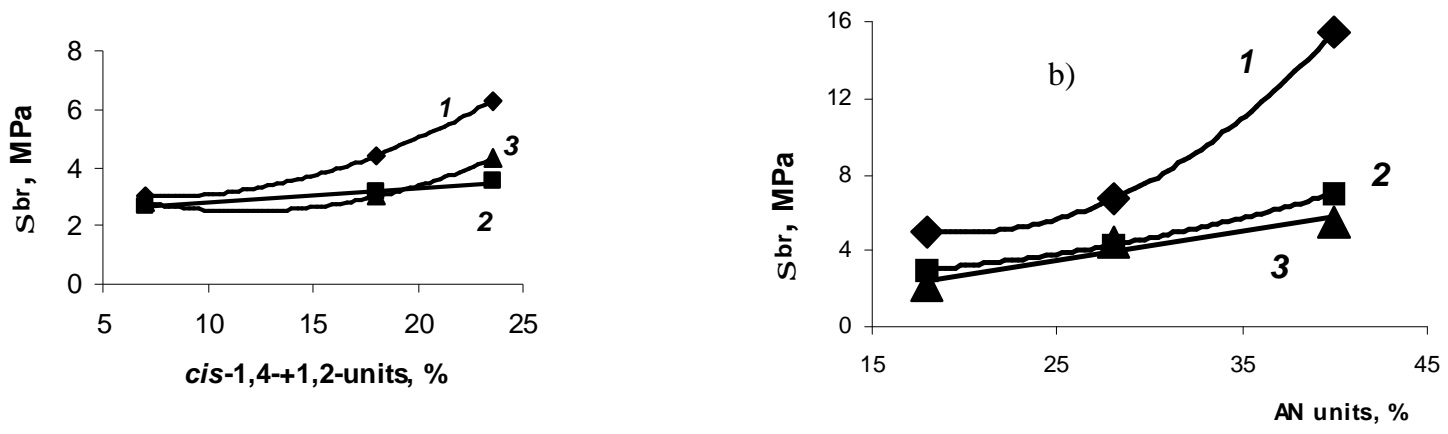

Fig. 5. The conditional tensile strength $\sigma_{b r}$ of the NBR covulcanizates plotted against the content of $c i s-1,4-+1,2-$ units (a) and AN units (b): unmodified Elastokam 6305 (1); EPDM-60(I) (2) and EPDM-40 (3)

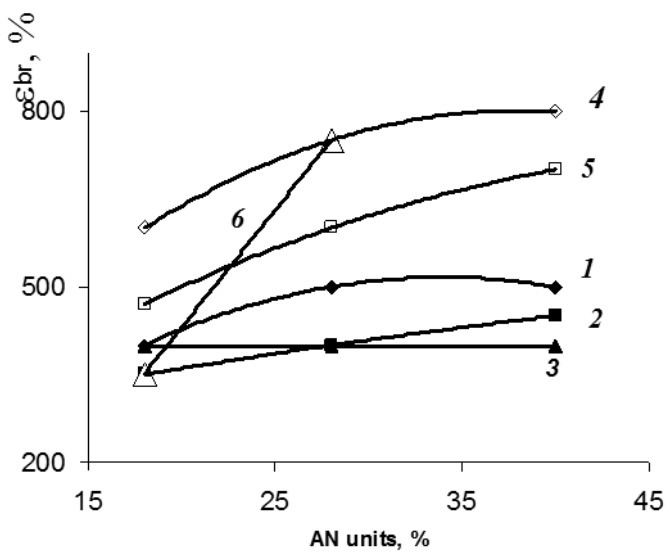

Fig. 6. The relative elongation at break $\varepsilon_{b r}$ plotted against the content of AN units (a) for NBR covulcanizates with Elastokam 6305 (1, 4); EPDM-60(I) $(2,5)$ and EPDM-40 $(3,6)$ for unmodified samples (1-3) and samples modified by the sulfur-containing accelerating agent (4-6) 


\section{Conclusions}

Not only the composition of EPDM but also the stereoregularity of propylene units affects the efficacy of the modification of EPDM during its sulfur vulcanization in the blends with NBR.

The modification of EPDM to increase the ozone resistance of the crosslinked blends with NBR leads to the improvement of the characteristics of covulcanizates only when certain brands of EPDM are used and certain methods of introduction of the cure system are applied.

\section{References}

[1] Livanova N.: Vysokomolek. Soed. A, 2006, 48, 1424.

[2] Livanova N.: [in:] Zaikov G. and Kirshenbaum G. (Eds.), Chemical Physics and Physical Chemistry: Step into the Future.

Nova Science Publishers, Inc., New York 2007, 25.

[3] Livanova N., Lyakin Yu., Popov A. and Shershnev V.: Vysokomolek. Soed. A, 2007, 49, 79.

[4] Livanova N., Lyakin Yu., Popov A. and Shershnev V.: Vysokomolek. Soed. A, 2007, 49, 465.

[5] Gould R. (Ed.): Multicomponent Polymer Systems. American Chemical Society, Washington 1972.

[6] Lednev Yu., Zakharov N., Zakharkin O. et al.: Kolloidn. Zh., 1977, 39, 170.

[7] Baknell K., Pol D. and Kuleznev V. (Eds.): Polymernye Smesi. Nauka i Technologii, S-Peterburg 2009.

[8] Lipatov Yu. (Ed.): Fizicheskaya Khimiya Mnogokomponentnykh System. Naukova dumka, Kiev 1986.

[9] Kuleznev V.: Vysokomolek. Soed. B, 1993, 35, 1391.

[10] Kuleznev V. and Voyutskii S.: Kolloidn. Zh., 1973, 35, 40.

[11] Livanova N., Shershnev V., Dudnik M. et al.: Kauchuk i

Resina, 2007, 5, 13.

[12] Dechant J., Danz R., Kimmer W. and Schmolke R.: Ultrarotspektroskopische Untersuchungen an Polymeren. Akademie, Berlin 1972.

[13] Kozlova N., Sukhov F. and Bazov V.: Zavodskaya Laboratoriya, $1965, \mathbf{3 1}, 968$.
[14] Kissin Yu., Tsvetkova V. and Chirkov N.: Vysokomolek. Soed. A, 1968, 10, 1092.

[15] Kissin Yu., Popov I., Lisitsin D. et al.: Proizvodstvo Shin, Rezino-Techn. i Asbesto-Techn. Izd., 1966, 7, 22.

[16] Shershnev V., Yulovskaya V., Lyamkina N. et al.: Vysokomolek. Soed. A, 1999, 41, 462.

[17] Livanova N., Karpova S. and Popov A.: Vysokomolek. Soed. A, 2011, 53, 2043.

[18] Livanova N., Karpova S. and Popov A.: Vysokomolek. Soed. A, 2003, 45, 417.

[19] Livanova N., Evreinov Yu., Popov A. and Shershnev V.: Vysokomolek. Soed. A, 2003, 45, 903.

[20] Livanova N., Karpova S. and Popov A.: Plast. Massy, 2005, 2, 11.

[21] Nesterov A.: Spravochnik po Fizicheskoy Khimii Polimerov. Naukova dumka, Kiev 1984.

Received: January 21, 2015 / Revised: February 20, 2015 / Accepted: J une 11, 2015

\section{ВПЛИВ СТЕРЕОРЕГУЛЯРНОСТІ ПРОПІЛЕНОВИХ ЛАНОК В МОДИФІКОВАНИХ ЕТИЛЕН-ПРОПІЛЕН-ДІЕНОВИХ ЕЛАСТОМЕРАХ НА ОЗОНОСТІЙКІСТЬ КО-ВУЛКАНІЗАТІВ 3 АКРИЛОНІТРИЛ-БУТАДІЕНОВИМИ КАУЧУКАМИ}

Анотація. Показано, щзо модифікування етилен-пропілен-дієнових еластомерів при додаванні фрагментів прискорюючої речовини для поліпшення їх сумісності з акрилонитрилбутадієновими каучуками і зменшення швидкості розкладу озону є ефективним тільки у випадку низької стереорегулярності пропіленових ланок у кополімері етилен-пропілен-дієн, коли зииту систему додають до акрилонітрил-бутадієнового каучуку. Визначено, щчо при високій ізотактичності пропіленових фрагментів в ланцюзі етилен-пропилен-дієнових еластомерів їх модифікаиія знижує озоностійкість зиитих структур незалежно від режиму введення структуруючих систем.

Ключові слова: акрилонітрил-бутадієновий каучук, етилен-пропілен-дісновий еластомер, озон-індукований розклад, сумісність, структура міжфазових шарів, пропіленові ланки, стереорегулярність. 
